GU J Sci, Part C, 6(3): 524-535 (2018)

Gazi Üniversitesi
Fen Bilimleri Dergisi
PART C: TASARIM VE TEKNOLOJI
dergipark.gov.tr/http-gujsc-gazi-edu-tr

\title{
Yeni Nesil Modüler Taşıma Aracının 3-Serbestlik Derecesinde Manyetik Yastıklama Hava Aralı̆̆ı Kontrolü
}

\author{
Kadir ERKAN ${ }^{1, *}$

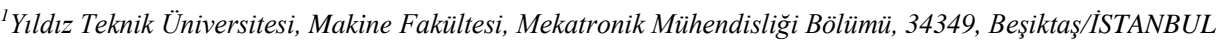

\begin{abstract}
$\ddot{O} \mathbf{z}$
Makale Bilgisi

Bașvuru: 14/12/2017

Düzeltme: 29/04/2018

Kabul: 08/06/2018

Anahtar Kelimeler

Manyetik yastik

3-serbestlik derecesinde kontrol

Karma elektromıknatıs

I-PD kontrol

Bu çalışmada, 3 adet doğrusal motorla karma elektromıknatısların bir araya getirilmesiyle elde edilen manyetik yastıklama temeline dayalı bir taşıma aracı, yeni nesil modüler bir taşıma sistemi meydana getirmek için önerilmiştir. Sonlu elemanlar metodu ile manyetik yastıklama kuvvetlerinin 3 boyutlu analizi yapılmıştır. Önerilen sistem doğrusal olmayan dinamiklere sahip olup, doğrusallaştırıldığında dahi kontrol açısından kararsız sistem özelliği göstermektedir. Sistemi kararlı hale getirecek denetleyici tasarımlarını gerçekleştirmek için 3eksende hareket dinamiğine karşılık gelen doğrusal sistem modelleri geliştirilmiştir. Her bir eksen takımı için geliştirilen doğrusal modeller kullanılarak kararlılığı sağlayan ve aynı zamanda verilen referansı takip eden denetleyiciler I-PD denetleyici topolojisi dikkate alınarak tasarlanmıştır. I-PD denetleyici klasik PID denetleyici ile karşılaştırıldığında; orijine yakın sıfır atamasını ortadan kaldırarak kararlılığı tehdit eden aşırı üst aşımları önler. Denetleyici tasarımlarında, muadillerine göre daha kolay tasarım ve uyarlama imkânı sağlayan kanonik polinom yaklaşımı ile katsayı diyagramı metodu kullanımı önerilmiştir. 3-serbestlik derecesinde manyetik yastıklama kontrolü deneysel olarak gerçekleştirilmiş, önerilen kontrol yaklaşımının etkinliği ve başarısı deneysel olarak gösterilmiştir.
\end{abstract}

Keywords

Manyetik levitation

3-degree of freedom

control

Hybrid electromagnet

I-PD control

\section{3-Degree of Freedom Gap Clearance Control of A New Generation Maglev Conveyance Vehicle}

\begin{abstract}
In this study, a transport vehicle based on magnetic levitation technology, which is obtained by combining 3 linear motors and hybrid electromagnets, has been proposed for providing a flexible and modular conveyance system. The magnetic suspension forces have been obtained using 3-dimensional finite element analysis. The proposed system has nonlinear dynamics and shows unstable system characteristics from the point view of control engineering, even for the linearized form. Linear system models corresponding to the 3-axis motion dynamics have been developed to implement controller designs that will stabilize the system. Using the linear models developed for each motion axis, the controllers providing stability and at the same time tracking capability the given reference have been designed considering the topology of I-PD controller. When the I-PD controller is compared with the conventional PID controller; it removes the zero close to origin and eliminates the excessive overshoot that threatens the stability. In controller designs, the use of the coefficient diagram method with the canonical polynomial approach, which provides considerably easier design and adaptation than the counterparts, has been proposed. The magnetic levitation control in the 3-degree of freedom was experimentally performed on the test setup, and the effectiveness of the proposed control approach was successfully demonstrated and verified.
\end{abstract}

\section{GİRIŞ (INTRODUCTION)}

Manyetik yastıklama sistemleri mekanik temasın yer almadığı; aşınma, sürtünme, titreşim, gürültü vb. mekanik problemlerden bağımsız, yüksek doğruluk ve hassasiyette hızlı ve tekrarlanabilir çalışma ortaya koyan sistemlerdir. $\mathrm{Bu}$ avantajları nedeniyle, kitle taşıma araçlarında, temassız yataklamalarda, titreşim 
izolasyon kontrolünde, biyomedikal aletlerde, rüzgar türbinlerinde, temiz odalarda mikro boyutlardan makro boyutlara kadar anahtar bir teknoloji olarak kullanım potansiyeline sahiptir [1,2].

Elektromıknatıslara kalıcı mıknatıs dilimlerinin eklenmesi ile elde edilen karma elektromıknatıslar; enerji kayıplarını büyük oranlarda azaltırken, elektromıknatıs boyutunun ve ağırlığının küçülmesine olumlu katk1 sağlar [2-5]. Manyetik yastıklama ve yataklama sistemlerinde sıklıkla kullanılan U ve E şekilli elektromıknatıslar ile ancak tek serbestlik derecesinde yastıklama ya da yataklama sağlanabilir. Fakat pek çok endüstriyel uygulamada tek serbestlik derecesinde kontrol yeterli olmayıp, dengeli yastıklama ya da yataklama birden fazla elektromıknatısın farklı serbestlik derecelerini kontrol edecek biçimde konfigüre edilmesiyle elde edilir [1,2]. [5]'de 4 adet miknatıs kutbunun bir araya getirilmesiyle elde edilen 4kutuplu karma elektromıknatıs ünitesi yek pare bir yapı ile 3-serbestlik derecesinde dengeli yastıklamaya imkân verir. Diğer yandan, 3 adet U şekilli karma elektromıknatısın simetrik geometride yerleşimi ile elde edilen sistem hem dengeli yastıklama sağlarken hem de 3-serbestlik derecesinde yastıklama kontrolüne imkân tanır [3,4]. Dengeli biçimde manyetik olarak yastıklanan ünitenin düzlemde hareketi taşıma sistemleri için kritik öneme haizdir. Düzlemde sürme ve yönlendirme işlemi temel olarak doğrusal motorlarla gerçekleştirilir [1-3,5]. Yastıklanan ünitenin düzlemde sürülmesinde genel olarak iki topolojiden birisi kullanılır; ilk topoloji de doğrusal motorlar yastıklanan ünite üzerinde olmayıp bir düzlem boyunca sabit olarak mesnetlenir [5], ikinci topolojide ise motorlar ünite üzerine karma elektromıknatıslarla birlikte yerleştirilir [3]. Bu çalışmada Şekil 1'de gösterilen, doğrusal motor tasarım ve kontrol maliyetini düşüren fakat enerji verimliliği ilkine göre daha düşük olan ikinci topoloji dikkate alınmış ve özgün bir tasarım ortaya konmuştur. Bu çalışmada sadece hava aralığı kontrolü ele alınmıştır.

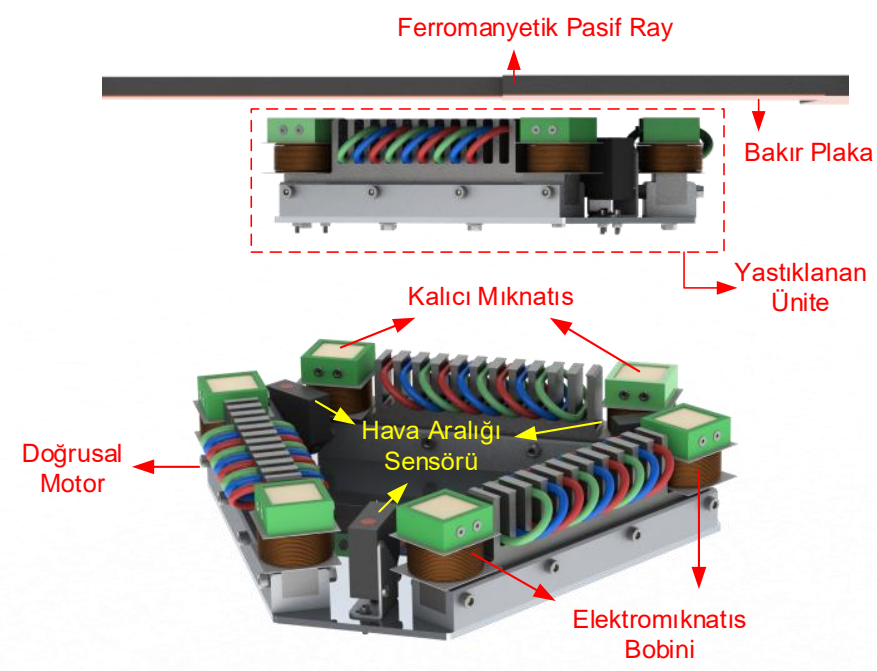

\section{Şekil 1. Ü̧̧ doğrusal motor ve karma elektromıknatısların bir araya getirilmesiyle elde edilen manyetik} yastıklama ünitesi.

Özgün tasarımımızın literatürdeki benzer tasarımlardan, [3,5], en önemli üstünlüğü karma elektromıknatıs ile doğrusal motorun aynı nüve üzerinde yer almasıdır. Böylece yek pare bir yapı elde edilerek hem üretim maliyeti hem de montaj maliyeti azaltılmıştır.

Manyetik yastıklama ve yataklama sistemlerinde itme yada çekme kuvveti ile yastıklama hava aralığındaki ilişki doğrusal olmayan bir karakteristik gösterip, kontrol açısından kararsız bir yapı oluşturmaktadır [1,2]. Kararlı manyetik yastıklama, hava aralığını istenen değerde tutmayı sağlayan, kontrolün elektromıknatıs bobinlerinden geçirilecek akımla sağlandığı geri beslemeli kontrol ile oluşturulabilmektedir [1-15]. Denetleyici tasarım yaklaşımları olarak literatürde pek çok yöntem manyetik yastıklar için önerilmiştir. [6]'da durum geri beslemeli yapı ile orantı - integral - türev (PID) bileşenlerinden oluşan denetleyici topolojileri çalışılmıştır. Durum geri beslemeli kontrol yaklaşımı ancak bütün durumların ölçülebilir ya da erişilebilir olduğu hallerde kullanıma müsaittir. Dolayısıyla, maliyeti artıran pahalı durum ölçme sensörleri ya da karmaşık algoritmalarla yazılımsal olarak tasarlanan ve ancak 
belli kısıtlar altında verimli olarak çalışan durum gözlemcileri ile bu problemin üstesinden gelinmektedir. Durum geri beslemeli kontrol yöntemi doğrusal kontrol yaklaşımları ile çözülebilmektedir. Diğer taraftan doğrusal olmayan kontrol tasarım yaklaşımları da yoğun bir şekilde literatürde hali hazırda çalışılmaktadır [7-13]. [7]'de geri beslemeli doğrusallaştırma metodu dikkate alınarak normal bir elektromıknatıs için uygulanmıştır. Karma elektromıknatıslarda çalışma noktası enerji tüketimini azaltmak için akımın çok küçük değerler aldığ 1 çalışma bölgesinde kararlılaştırılmaya çalışılır $[2,4]$. Bu durum, geri beslemeli doğrusallaştırma yaklaşımında, özellikle akımın sıfır ve sıfıra yakın değerler alması hallerinde kontrol işaretinin tanımsız olmasına neden olur ve sistem kararsızlığa sürüklenebilmektedir. Ayrıca sistemin tam olarak modellenmesine ihtiyaç duyar. Model bilgisine tam olarak gereksinim duymayan bulanık mantık yaklaşımları ile denetleyici tasarımları bulunmaktadır $[4,8,9]$. Bu yaklaşımlarda, doğrusal olmayan model belirli noktalarda doğrusallaştırılır ve her bir model için denetleyici tasarımı yapılır ve bir kural tablosu ile denetleyiciler bir araya getirilerek kontrol işaretinin üretilmesi sağlanır. Tasarım zahmetli olup yüksek hesaplama kabiliyetine sahip bilgisayarların kullanımını gerekli kılar. Ayrıca denetleyici parametrelerinin uyarlanması ve optimum değerlerin bulunması zaman alır. Kararlılığın kolay bir şekilde kanıtlanamaması bir diğer zayıf yönüdür. Kayan kipli kontrol yaklaşımları yoğun şekilde çalışılan konular arasındadır [10-12]. Fakat kontrol işaretinde ortaya çıkan yüksek frekanslı değişimler (çatırtılar) bu yaklaşımın önündeki en büyük pratik problemlerden bir tanesidir. $\mathrm{Bu}$ problemi aşmak için yüksek dereceden kayan kipli denetleyici tasarımlarının diğer yöntemlerle kombine kullanımı önerilmiştir [10-13]. Bu yaklaşımların başarısı ise yüksek hızı kontrol çevrimine ve çıkış büyüklüklerinin hassas ve gürültüsüz ölçümüne bağlıdır. Ayrıca, güçlü matematik alt yapısı gerektirdiğinden alanda çalışan mühendisler tarafından tasarımı kısa sürede yapılamamaktadır [5]. Model öngörülü kontrol yaklaşımları da kayan kipli kontrol de olduğu gibi yüksek hesaplama ve kontrol çevrimine sahip hızlı işlemcilere gereksinim duyarak gerçeklemeyi maliyetli hale getiren unsurlar içermektedir [14].

PID denetleyiciler kapalı çevrim kontrole ihtiyaç duyulan hemen hemen her alanda tasarımlarının ve adaptasyonlarının kolaylığı ve basit donanımlarla gerçekleyebilmeleri bir takım avantajlardan dolayı yaygın bir şekilde yer bulmaktadır [15]. PID katsayılarının bulunmasında ampirik metotlar kullanılabildiği gibi gelişmiş ve halihazırda gelişmekte olan metotlar kullanılmaktadır [15-17]. [16]'da kesirli diferansiyel denklem yaklaşımı sunulmuştur. Standart olmayan ileri matematik bilgisi gerektirmesi bu yaklaşımın en zayıf yönlerinden birisidir. Diğer taraftan tasarımın klasik metotlara göre zorluğu benzetiminin nispeten zor oluşu diğer bir dezavantajıdır. Benzer şekilde [17]'de ifade edilen model referans yaklaşımı ise hem tasarım zorluğu hem de hesaplama maliyeti getirmektedir. $\mathrm{Bu}$ çalışmada, önerilen manyetik yastık ünitesinin 3-serbestlik derecesinde kontrolü için katsayı diyagramı metodunu kullanarak kanonik polinom yaklaşımı ile I-PD denetleyici tasarımı önerilmiştir. Geleneksel PID denetleyici yapısı doğrusallaştırılmış model ile birlikte kapalı çevrim formunda değerlendirildiğinde frekans tanım bölgesinin orijine yakın kısımlarına kapalı çevrim sıfırı atayarak geçici rejimde yastıklama hava aralığı performansının azalmasına neden olmaktadır [5]. Bunun önüne geçmek için I-PD yapısı tasarımlarda kullanılmıştır. Kanonik polinom yapısı ile katsayı diyagram metodunun denetleyici tasarımlarında kullanımı [18]'de önerilmiştir. [19]'da ise bu yaklaşımın zaman gecikmeli sistemlerde gürbüz bir kontrol yapısı ortaya koyduğu gösterilmiştir. Kanonik polinom yaklaşımı ile katsayı diyagram metodunun bilinen diğer metotlara göre en büyük avantajları $[5,18,19]$;

a. Sistematik bir yaklaşım olup, denetleyici parametrelerinin hesaplanması oldukça kolaydır. Ziegler Nichols gibi literatürde bilinen yöntemlere göre çok daha kolay hatırlanabilir ve uygulanabilir.

b. Performans, kararlılık ve gürbüzlük arasındaki ilişki kolay bir şekilde kavranarak, denetleyici parametreleri çok kolay bir şekilde uyarlanabilir.

c. Katsayı diyagramı ile kararlılık sınırları, performans ve gürbüzlük görsel hale getirilebilir. Çok amaçlı denetleyici tasarımları daha kolay kısa sürede neticelendirilebilir.

\section{MODELLEME ve DENETLEYİCI TASARIMI (MODELLING and CONTROLLER DESIGN)}

\subsection{Doğrusal Motor - Karma Elektromıknatıs Modeli}

Doğrusal motorla aynı nüve üzerinde birleşik karma elektromıknatıstan oluşan 3 yastıklama ve tahrik eleman1, eşkenar üçgen oluşturacak formda bir tabla üzerinde bir araya getirilerek Şekil 1'de görülen 
taşıma aracı teşkil edilmiştir. Karma elektromıknatıslarla enerji verimli yastıklama sağlanırken, doğrusal motorlarla düzlemsel hareketin ferromanyetik pasif ray altında eldesi amaçlanmıştır. Yastıklama ve tahrik elemanının aynı nüve üzerinde bulunması, hem karma elektromıknatıs hem de motor faz akımlarının aynı zaman diliminde enerjilendirilmesi durumunda etkileşim riskini ortaya çıkarak model geliştirme işlemini problemli hale getirebilmektedir. Bu bağlamda özellikle yastıklama etkileşim ve girişim miktarını belirlemek için Ansys ${ }^{\circledR}$ Maxwell ${ }^{\circledR}$ paket programı kullanılarak 3-boyutlu sonlu elemanlar analizi (SEA) ile manyetik akı dağılımı incelenmiştir. Analizde kullanılan ağ yapısı ve manyetik akı dağılımı Şekil 2'de gösterilmiştir.

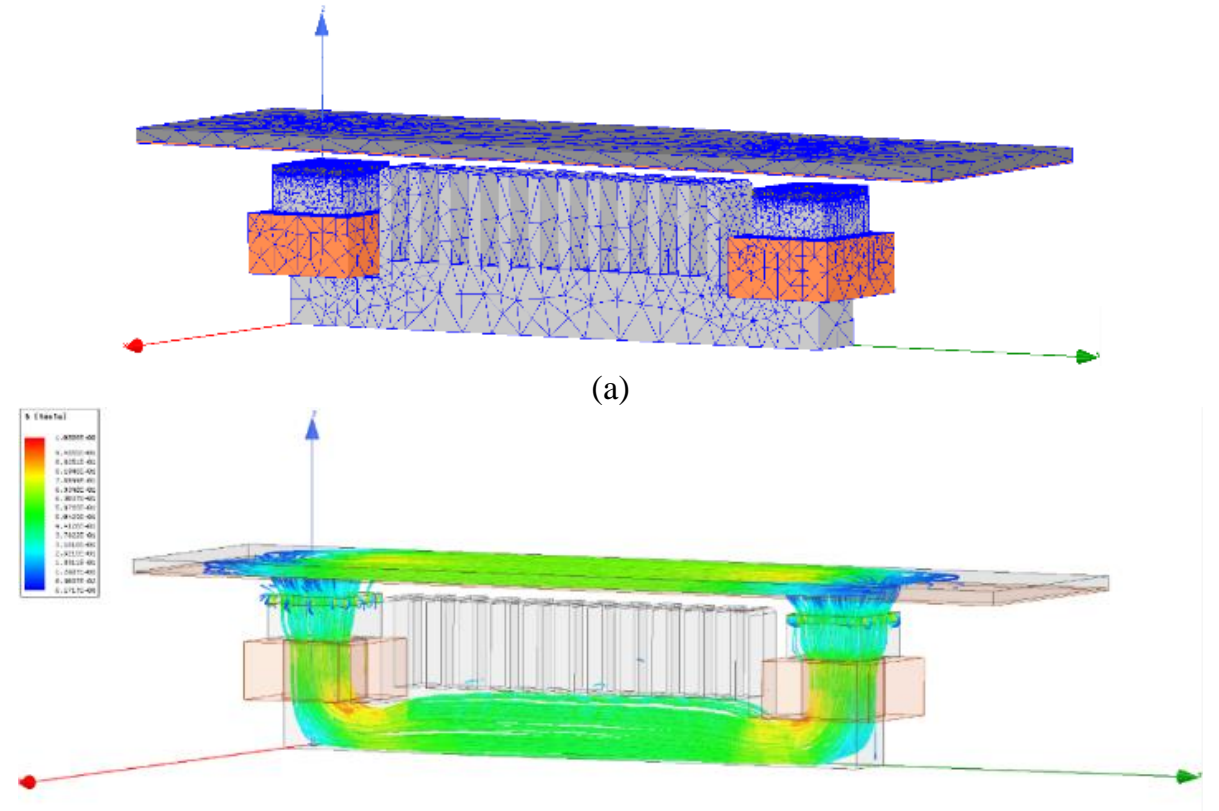

(b)

Şekil 2. Yastıklama ve tahrik ünitesi; (a) 3-boyutlu SEA ăg yapısl, (b) 3-boyutlu SEA akl dağılımı

Ak1 dağılımından görüleceği üzere, karma elektromıknatıs tarafından üretilen ak1, tamamen pasif ferromanyetik ray tarafından taşınmakta motor olukları üzerinden geçememektedir. Bu durumda, yastıklama ünitesi U şekilli karma elektromıknatıs olarak kabul edilip manyetik devre yaklaşımı ile analiz edilebilecektir. U şekilli elektromıknatısa ilişkin çekme kuvveti;

a. histeresiz, doyma ve girdap akım etkilerinin olmadığı,

b. ferromanyetik kısımların manyetik geçirgenliğinin sonsuz olduğu ve kalıcı mıknatısa ilişkin manyetik geçirgenliğin boşluğa eşit olduğu

c. kutup başlarında ve gövdenin muhtelif bölgelerinde akı saçılması ve kaçağı olmadığı, kabulleri ile manyetik devre yaklaşımı kullanılarak (1)'deki gibi elde edilir [1,2].

$$
f_{e}(i, g)=N^{2} \mu_{0} S \frac{\left(i+I_{p m}\right)^{2}}{\left(g+L_{p m}\right)^{2}}=k \frac{\left(i+I_{p m}\right)^{2}}{\left(g+L_{p m}\right)^{2}}
$$

(2.1)'de $\mathrm{N}$ bobin sarım sayısını, $\mu 0$ boşluğun manyetik geçirgenliğini, $\mathrm{S}$ kutup yüzey alanını, i bobin akımını, Ipm kalıcı mıknatısın akım eşdeğer etkisini, g efektif hava aralığını, Lpm kalıcı mıknatıs kalınlığını ifade etmektedir. Çekme kuvveti $\left(f_{e}\right)$ doğrusal olmayan bir özellik göstermektedir. 3-boyutlu SEA'ye ilişkin kuvvet - hava aralığı - akım ilişkisi Şekil 3'deki gibi manyeto-statik analiz ile elde edilmiş, (2.1)'in doğruluğu da kanıtlanmıştır. Hareket dinamiği ise;

$$
m \frac{d^{2} g}{d t^{2}}=f_{d}+m g-f_{e}(i, g)
$$

olarak elde edilir. $m$ yastıklana kütleyi, $g$ yerçekimi ivmesini ve $f_{d}$ bozucu giriş kuvvetini ifade etmektedir. Elektriksel dinamik ise; 


$$
e(t)=R i+\frac{\partial \lambda}{\partial t}=R i+\frac{\partial \lambda}{\partial i} \frac{d i}{d t}+\frac{\partial \lambda}{\partial g} \frac{d g}{d t}
$$

$R$ bobin direncini, $\lambda$ halkalanan akı bağını göstermektedir. (2.2) ve (2.3) yastıklama ve tahrik elemanının dinamik modelini ifade eder ve doğrusal olmayan formdadır. Kanonik polinom ile katsayı diyagramı metodunu kullanabilmek için (2.2) ve (2.3) ifadeleri ( $i=i_{0}$ ve $g=g_{0}$ ) çalışma noktasında doğrusallaştırılır. Enerji tüketimini minimize eden çalışma noktası akımın sıfır olduğu yani yastıklamanın sadece kalıcı mıknatıs çekme kuvvetiyle sağlandığı noktadır. Akım için bu nokta yani $\left(i=i_{0}=0\right)$ çalışma noktası dikkate alınır. Buna göre doğrusal dinamik

$$
\begin{aligned}
& f_{e}\left(i_{0}=0, g_{0}\right)=m g \\
& m \frac{d^{2} \Delta g}{d t^{2}}=K_{g} \Delta g-K_{i} \Delta i+f_{d} \\
& K_{g}=-\left.\frac{\partial f_{e}}{\partial g}\right|_{i_{0}}=2 k \frac{\left(I_{p m}+i_{0}\right)^{2}}{\left(L_{p m}+g_{0}\right)^{3}} ; \quad K_{i}=\left.\frac{\partial f_{e}}{\partial i}\right|_{i_{0}}=2 k \frac{\left(I_{p m}+i_{0}\right)}{\left(L_{p m}+g_{0}\right)^{2}} \\
& \frac{d \Delta i}{d t}=-\frac{R}{L} \Delta i+\frac{K_{v}}{L} \frac{d \Delta g}{d t}+\frac{1}{L} \Delta e \\
& K_{v}=-\left.\frac{\partial \lambda}{\partial g}\right|_{i_{0}}=2 k \frac{\left(I_{p m}+i_{0}\right)}{\left(L_{p m}+g_{0}\right)^{2}} ; L=\left.\frac{\partial \lambda}{\partial i}\right|_{i_{0}}=\frac{2 k}{\left(L_{p m}+g_{0}\right)}
\end{aligned}
$$

Her bir karma elektromıknatıs için denetleyici tasarımı ile kararlılaştırma, lokal kontrol olarak bilinmekte ve eksen dinamiklerini içermemektedir [1,2]. Bu durumu ortadan kaldırmak için, akım ve hava aralığ dönüşüm matrisleri ile global eksen takımları için doğrusallaştırılmış dinamik modeller elde edilerek global denetleyici tasarımı dikkate alınmıştır. Dönüşümlerde kullanılan geometrik detaylar Şekil 4'de verilmiştir. (2.9)'da her bir yastıklama elemanın hava aralığı yönü $\left(\Delta g_{A}, \Delta g_{B}, \Delta g_{C}\right)$ lokal eksen yönünü göstermektedir. Şekil 4'de verilen global eksen takımı taşıtın ağırlık merkezini orijin kabul ederek tanımlanmıştır. Yastıklama elemanlarına ilişkin çekme kuvvetleri ( $\left.f_{e A}, f_{e B}, f_{e C}\right)$, geometrik ilişki dikkate alınarak global eksen takımları üzerine izdüşürülür. Neticede, (2.10)' da verilen akım dönüşüm matrisi elde edilir. Dönüşümlerin her bir yastıklama ünitesi, $(A, B, C)$, için hem hareket dinamiğine, (2.5), ve hem de elektriksel dinamiğe (2.7) uygulanması ile global eksen takımları için dinamik denklemler bulunur. $z$ global eksenine karşılık düşen transfer fonksiyonu (2.11)'de verilmiştir. Diğer eksen takımları için ise indisler ve eksen parametreleri haricinde (2.11)'de verilen denklem formu geçerli olur.

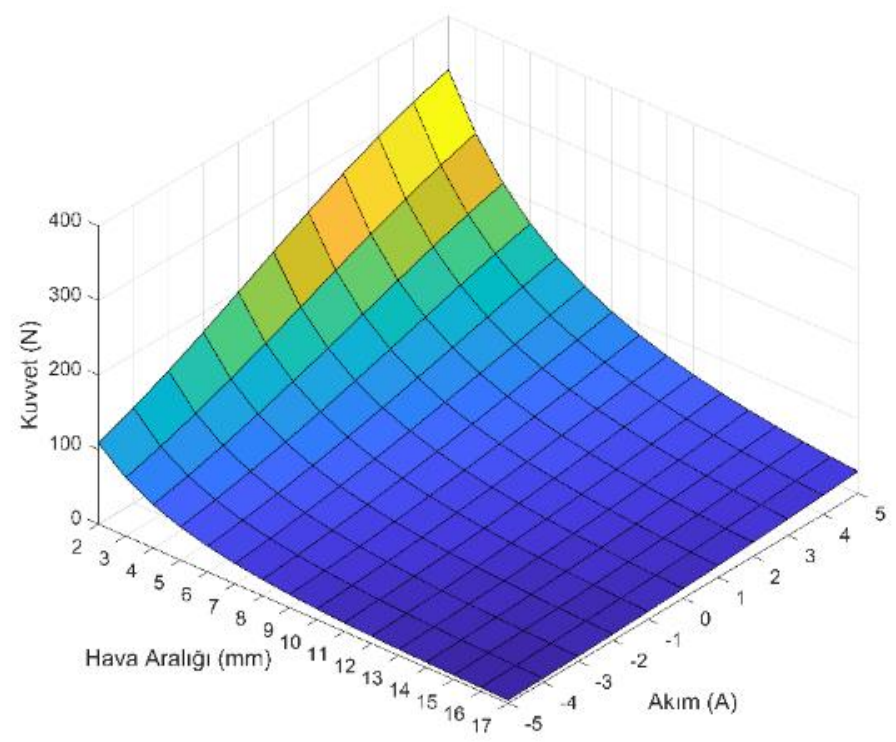

Şekil 3. 3-boyutlu SEA kuvvet - hava aralı̆̆ - akım ilişkisi. 


$$
\begin{aligned}
& {\left[\begin{array}{c}
\Delta z \\
\Delta \alpha \\
\Delta \beta
\end{array}\right]=\left[\begin{array}{ccc}
-\frac{1}{3} & -\frac{1}{3} & -\frac{1}{3} \\
-\frac{2}{3 l_{e}} & \frac{1}{3 l_{e}} & \frac{1}{3 l_{e}} \\
0 & -\frac{1}{\sqrt{3} l_{e}} & \frac{1}{\sqrt{3} l_{e}}
\end{array}\right]\left[\begin{array}{l}
\Delta i_{A} \\
\Delta i_{B} \\
\Delta i_{C}
\end{array}\right]=T\left[\begin{array}{l}
\Delta g_{A} \\
\Delta g_{B} \\
\Delta g_{C}
\end{array}\right]} \\
& {\left[\begin{array}{c}
\Delta i_{z} \\
\Delta i_{\alpha} \\
\Delta i_{\beta}
\end{array}\right]=\left[\begin{array}{ccc}
\frac{1}{3} & \frac{1}{3} & \frac{1}{3} \\
1 & -\frac{1}{2} & -\frac{1}{2} \\
0 & \frac{\sqrt{3}}{2} & -\frac{\sqrt{3}}{2}
\end{array}\right]\left[\begin{array}{l}
\Delta i_{A} \\
\Delta i_{B} \\
\Delta i_{C}
\end{array}\right]=H\left[\begin{array}{c}
\Delta i_{A} \\
\Delta i_{B} \\
\Delta i_{C}
\end{array}\right]} \\
& \frac{\Delta z}{\Delta e_{z}}=\frac{K_{i z}}{L M s^{3}+M R s^{2}-R K_{z}}
\end{aligned}
$$

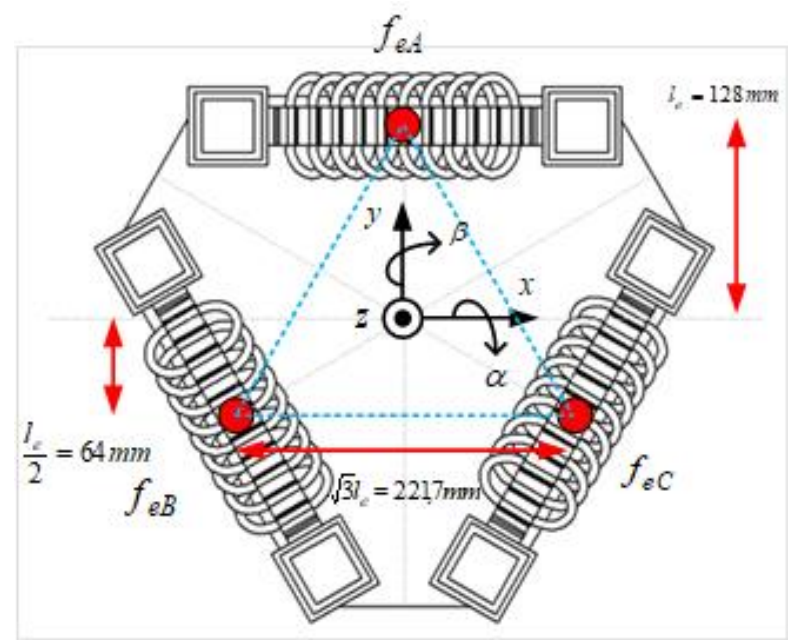

Şekil 4. Taşıt üzerinde tahrik ve yastıklama elemanlarının geometrik yerleşim detayları ve yastıklama kuvvetlerinin gösterimi.

\subsection{Kanonik Polinom Yaklaşımı ile I-PD Denetleyici Tasarımı}

Geleneksel PID denetleyici frekans tanım bölgesinde orijine yakın bölgelere kapalı çevrim sıfır yerleştirerek geçici rejimde sitem performansının kötüleşmesine, istenmeyen yüksek değerli üst aşıma ve kararlılığın bozulmasına neden olur [5]. Bu zayıflığı ortadan kaldırmak için; PID denetleyicinin diğer versiyonu olan, Şekil 5' gösterilen, I-PD denetleyici yapısının kullanılmasına karar kılınmıştır.

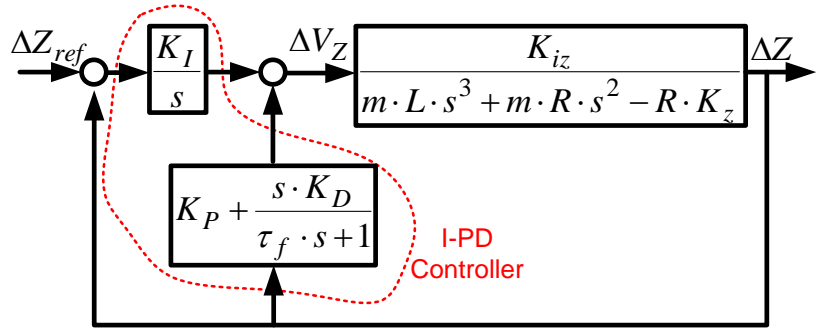

Şekil 5. z-ekseni I-PD denetleyici blok diyagramı.

n dereceli kanonik polinom (2.12)'de ifade edilmiştir.

$$
P(s)=a_{0} \cdot\left[\left\{\sum_{i=2}^{n}\left(\prod_{j=1}^{i-1} \frac{1}{\gamma_{j-1}^{j}}\right)(\tau \cdot s)^{i}\right\} \cdot \tau \cdot s+1\right]
$$

(2.12)'ye ilişkin tasarım parametreleri; $\tau$ zaman sabiti, $\gamma_{i}$ kararlılık indisi ve $\gamma_{i}{ }^{*}$ kararlılık sınırları olarak bilinir ve aşağıdaki gibi tanımlanmışlardır.

$$
\gamma_{i}=\frac{a_{i}^{2}}{a_{i-1} \cdot a_{i+1}}, \quad i=1, \Lambda, n-1
$$




$$
\gamma_{0}=\gamma_{n}=\infty, \quad \tau=a_{1} / a_{0}, \quad \gamma_{i}^{*}=\frac{1}{\gamma_{i-1}}+\frac{1}{\gamma_{i+1}}
$$

Eşdeğer zaman sabiti cevap hızını, kararlılık indisleri ve sınırları kararlılık marjinlerinin tayinini sağlar. Kararlılık indisleri özellikle parametrik model değişimleri olması durumunda gürbüzlüğün ne oranlarda ortaya konduğunun bir ölçüsüdür. Kanonik polinomun kararlılık şartları aşağıdaki gibi özetlenmiştir; kararsızlığı oluşturan gerek şart (2.15)'de kararlılığı sağlayan yeter şart ise (2.16)'da verilmiştir [18,19].

$$
\begin{aligned}
& \gamma_{i+1} \cdot \gamma_{i} \leq 1, \quad \exists i, i=2, \mathrm{~K}, n-1 \\
& \gamma_{i}>1.12 \gamma_{i}^{*}, \quad \forall i, i=2, \mathrm{~K}, n-1
\end{aligned}
$$

Pratikte, kararlılık indislerinin standart olarak belirlendiği yaklaşımlar bulunmaktadır. [18]'de Manabe kanonik formu olarak da bilinen (2.17)'nin kullanımı önerilmiştir. (2.17)'nin kullanımının dikkate değer

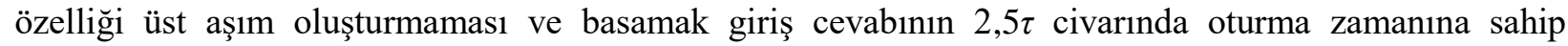
olmasıdır. En büyük avantajı ise bu katsayıların kolay hatırlanması ve denetleyici parametrelerinin kolay bir şekilde belirlenmesidir.

$$
\gamma_{i}=\{2,5 ; 2 ; 2 ; \ldots ;\}, \forall i, i=1, \ldots,(n-1)
$$

Şekil 5'de verilen blok diyagrama ilişkin kapalı çevrim transfer fonksiyonu (18)'de ifade edilmiştir.

$$
\frac{\Delta z}{\Delta z^{*}}=\frac{K_{I} K_{i z}}{(m L) s^{4}+(m R) s^{3}+\left(K_{D} K_{i z}\right) s^{2}+\left(K_{P} K_{i z}-K_{z} R\right)+K_{I} K_{i z}}
$$

(2.17)'de elde edilen karakteristik denklemin (payda) (2.12) ile eşlenmesiyle z-ekseni için I-PD denetleyici parametreleri (2.19)'daki gibi olur.

$$
\begin{array}{cc}
K_{P}=\frac{\gamma_{3}^{2} \gamma_{2} L^{2} R K_{z}+R^{3} m}{\gamma_{3}^{2} \gamma_{2} L^{2} K_{i z}}, & K_{I}=\frac{R^{4} m}{\gamma_{3}^{3} \gamma_{2}^{2} \gamma_{1} L^{3} K_{i z}} \\
K_{D}=\frac{R^{2} m}{\gamma_{1} L_{z} K_{i z}}, & \tau=\frac{a_{1}}{a_{0}}=\gamma_{1} \gamma_{2} \gamma_{3} \frac{L}{R}
\end{array}
$$

$\alpha$ ve $\beta$ eksenleri için, (2.19)'da kütle yerine ilgili eksenlere karşılık düşen atalet momentleri ve eksen parametreleri konularak I-PD katsayıları belirlenir. 3-serbestlik derecesinde kontrole ilişkin blok diyagram Şekil 6' da verilmiştir.

\section{DENEY DÜZENEĞİ ve DENEYSEL SONUÇLAR (EXPERIMENTAL SETUP and RESULTS)}

\begin{tabular}{|c|c|c|c|c|c|}
\hline Büyüklük - Birim & Değer & Büyüklük - Birim & Değer & Büyüklük - Birim & Değer \\
\hline $\mathbf{m}[\mathrm{kg}]$ & 17 & $z_{0}[\mathrm{~mm}]$ & 8,7 & $\alpha_{0}, \beta_{0}[\mathrm{rad}]$ & 0.0 \\
\hline$J_{a, \beta}\left[\mathrm{kg} \cdot \mathrm{m}^{2}\right]$ & 0.25 & $i_{z 0}[\mathrm{~A}]$ & 0.0 & $i_{a \theta}, i_{\beta 0}[\mathrm{~A}]$ & 0.0 \\
\hline$k\left[\mathrm{~N}^{2} / \mathrm{A}^{2}\right]$ & $6.15 \cdot 10^{-6}$ & $K_{z}[\mathbf{N} / \mathbf{m}]$ & 21305 & $K_{\omega}, K_{\beta}[\mathrm{Nm} / \mathrm{rad}]$ & 174,5 \\
\hline$I_{m}[\mathrm{~A}]$ & 14.875 & $K_{i z}[\mathbf{N} / \mathrm{A}]$ & 22,42 & $K_{i \omega}, K_{i \beta}[\mathrm{Nm} / \mathrm{A}]$ & 0,9567 \\
\hline $\boldsymbol{R}_{z, \alpha, \beta}[\mathbf{\Omega}]$ & 2,6 & $L_{z, \alpha, \beta}[\mathbf{H}]$ & 0.078 & $E_{p m} \quad[\mathrm{AT}]$ & 2975 \\
\hline
\end{tabular}

\subsection{Deney Düzeneği}

3-serbestlik derecesinde dengeli manyetik yataklama sağlayan sistem deney düzeneği oluşturulmuş ve 2.2'de açıklanan kanonik polinom tabalı I-PD denetleyici performansları gerçek sistem üzerinde denenmiştir. Deney düzeneğine ilişkin resim Şekil 7'de verilmiştir. Deney düzeneğine ilişsin parametreler deneysel olarak elde edilmiş ve Tablo 1'de gösterilmiştir.

Tablo 1. Deney düzeneği parametreleri 


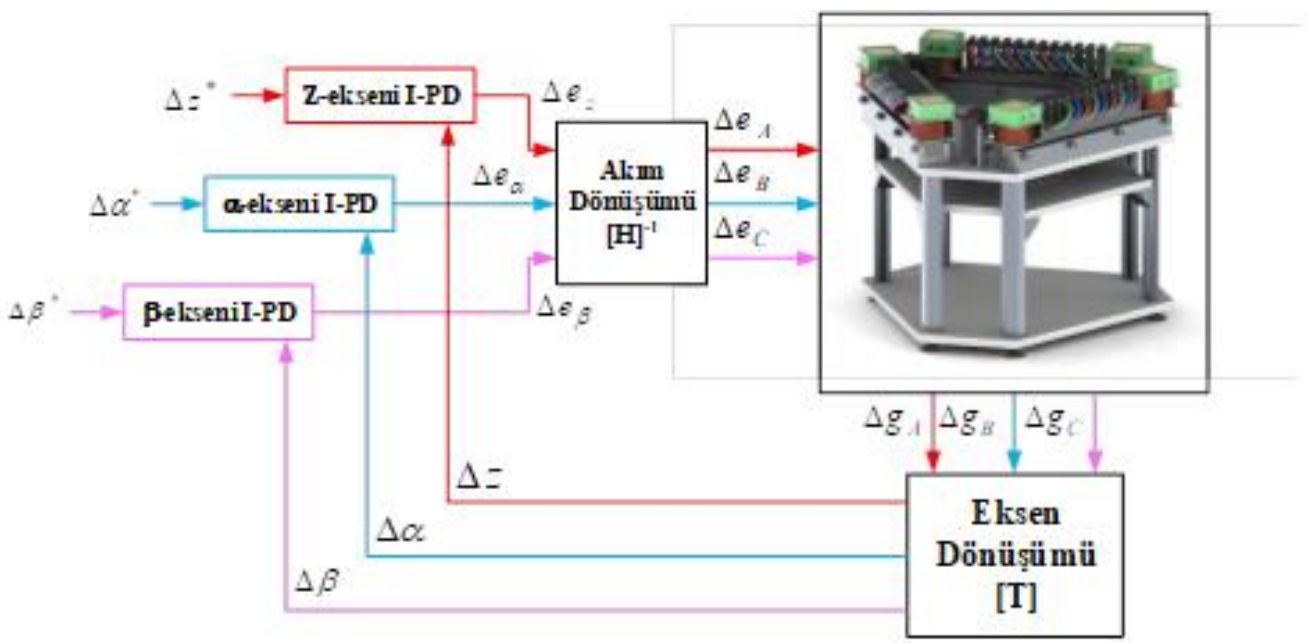

Şekil 6. 3-serbestlik derecesinde kontrol blok diyagrami.

I-PD denetleyiciler bir kontrol bilgisayarı ve veri işleme kartları kullanılarak dijital olarak gerçeklenmiş, kapalı çevrim örnekleme frekansı $2 \mathrm{kHz}$. olarak alınmıştır. Hava aralığı ölçümleri için temassız optik (LED) deplasman sensörleri kullanılmıştır. Akımlar ise flux-gate türü akım sensörleri vasıtasıyla ölçülmüş ve kontrol bilgisayarına sadece izleme amaçlı olarak analog giriş portundan gönderilmiştir. Sistemin işlevsel işaret akış şeması Şekil 8'de gösterilmiştir.

Deneysel çalışmalarda zaman sabiti $(\tau)$ yaklaşık olarak 0.1s olarak kabul edilmiştir. Bu değer, pek çok pratik çalışmada, manyetik yastıklama kontrolü için kabul edilen ve uygulanan bir değerdir [5]. Denetleyici tasarımları, kararlılık indisleri için Manabe kanonik formu, (2.17), her bir eksen takımı için deneysel olarak belirlenen model parametreleri, Tablo 1, (2.19)'da yerine konularak gerçekleştirilmiştir.

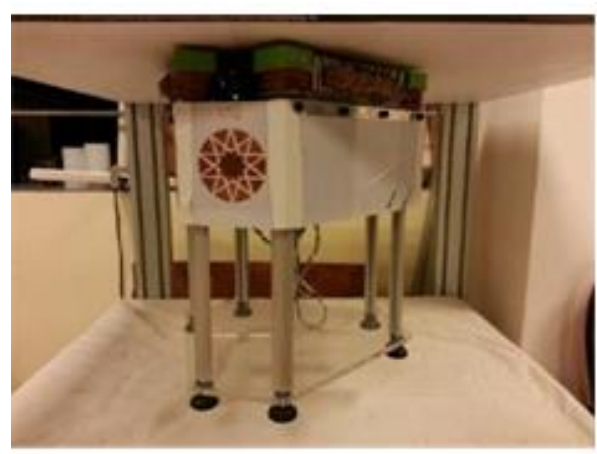

Şekil 7. Deney düzeneği resmi.

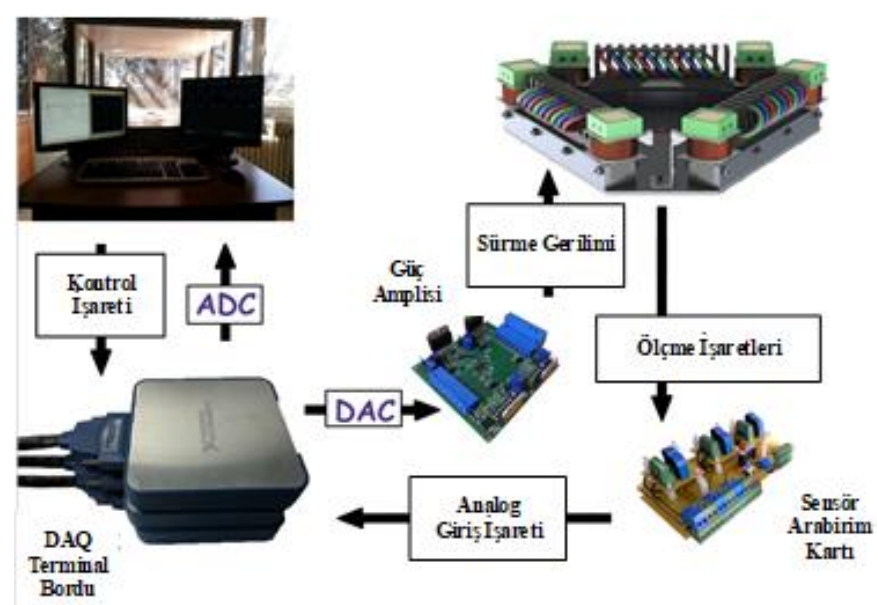

Şekil 8. Deney düzeneğinin işaret akışı ve fonksiyonel diyagramı. 
Deneysel çalışmalar iki durum dikkate alınarak gerçekleştirilmiştir. İlk durumda basamak referans girişi için denetleyici performansının geçici ve kalıcı rejimdeki cevabı gözlemlenmiştir. İkinci durumda ise gürbüzlük özelliği manyetik olarak yastıklanan araca yastıklama esnasında dış bir kuvvet uygulanarak gözlemlenmiştir.

\subsection{Referans Takip Performansının Gözlemlenmesi}

Şekil 9'da doğrusallaştırma noktası $\left(\mathrm{g}_{0}, \mathrm{z}_{0}\right)$ etrafında $\pm 2 \mathrm{~mm}$ basamak referans girişi için $z$-ekseni yer değiştirme (a) ve buna karşılık düşen akım cevabı (b) verilmiştir. Manabe kanonik form katsayıları kullanılmasına rağmen $\% 5$ 'den az bir miktarda üst aşım görülmüştür. Teroide üst aşımsız bir cevap beklenmektedir. Bunun temel nedeni model parametrelerinde öngörülmeyen belirsizliklerin olmasıdır. Genel itibariyle performans ve cevap kabul edilebilir seviyededir. Üst aşım miktarının azaltılması, özellikle $\gamma 1$ katsayısının 2,5'in birazcık üzerinde $(\sim 2,65)$ alınmasıyla çözülebilir. Bu ise, kolay bir biçimde gürbüzlük özelliğinin uyarlanması anlamına gelmektedir. Şekil 10'da $\pm 0,01$ rad basamak referans girişi için $\beta$-ekseni yer değiştirme (a) ve buna karşılık düşen akım cevabı (b) gösterilmiştir. $z$-ekseninde olduğu gibi öngörülemeyen model parametre kaymalarından dolay1 $\% 5$ 'in altında üst aşım görülmüştür. Ilgili $\gamma 1$ katsayısının 2,5 'in birazcık üzerinde $(\sim 2,65)$ alınmasıyla üst aşım problemi kolay bir şekilde çözülebilir. Şekil 11'de $\pm 0,01 \mathrm{rad}$ basamak referans girişi için $\alpha$-ekseni yer değiştirme (a) ve buna karşıllk düşen akım cevabı (b) gösterilmiştir. $z$ ve $\beta$ eksen cevaplarının aksine beklendiği gibi üst aşım değeri ortaya çıkmadan sistem çalıştırılabilmiştir. Referans takip cevapları beklenen performans isterlerini sağlar durumdadır, gerekli olması halinde özellikle kararlılık indeks parametreleri uyarlanarak hem cevap hem de gürbüzlük özelliği artırılabilmektedir.

\subsection{Bozucu Giriş Performansının Gözlemlenmesi}

Sisteme bütün eksenlere bozucu giriş yapacak biçimde simetrik olmayan $2,7 \mathrm{~kg}$ 'lık bir yük $t=2,9 \mathrm{~s}$ zamanı civarında uygulanmış ve $t=7,7 \mathrm{~s}$ civarında uzaklaştırılmıştır. Şekil $12,13 \mathrm{ve} 14$ 'de sırasıyla $z, \beta$ ve $\alpha$ eksen cevapları verilmiştir. Bozucu uygulanma esnasında, yerdeğiştirmelerde, anlık olarak sapmalar meydana gelmiş fakat I-PD denetleyici yapısı gereği kalıcı rejime geçildikçe bu sapmalar ortadan kalkmıştır. Yerdeğiştirmeler doğrusallaştırma noktasına çekilmiş ve yastıklama kararlılı̆̆ sağlanmıştır, bu esnada her bir eksen akımı dolayısıyla bobin akımı eklenen ağırlığı kompanze edecek miktarda artmıştır. Yük sistemden uzaklaştırıldığı anda yine yerdeğiştirmelerde anlık sapmalar ortaya çıkmış, kalıcı rejime geçildikçe doğrusallaştırılmış değerlerine geri dönmüşlerdir. I-PD denetleyicinin gürbüzlük özelliği bu deneysel çalışmalarda görülmüştür. Önerilen tasarım yaklaşımı bozucu giriş olması halinde bile performans isterlerini başarılı bir şekilde sağlamaktadır.

\section{SONUÇLAR (CONCLUSIONS)}

Çalışma kapsamında doğrusal motor nüvelerine entegre karma elektromıknatıslardan oluşan özgün bir taşıma aracı modüler ve esnek bir taşıma sistemi için önerilmiştir. Sistemin yastıklama mekanizmasına ilişkin doğrusal olmayan model irdelenmiş ve 3-boyutlu SEA ile yastıklama ve tahrik akıları arasında ayrımın ortaya çıktı̆̆ 1 sonucuna varılmıştır. Bu sonuçla yastıklamayı sağlayan karma elektromıknatıs modelleri manyetik devre yaklaşımı ile doğrusal olmaya formda elde edilmiştir. Sistemin kararlılı̆̆ını sağlamak için I-PD denetleyici kullanımı öngörülmüş ve denetleyici tasarımları kanonik polinom yaklaşımı ile yapılmıştır. Önerilen sisteme ilişkin deneysel düzenek tasarlanmış ve denetleyici tasarımları sisteme gerçek zaman kontrol bilgisayarı ile dijital formda uygulanmıştır. Deneysel çalışmalar iki kısma bölünerek sunulmuştur. İlk çalışmada kararlılık sağlanarak, ilgili eksen yerdeğiştirmelerinin basamak tipi referans yörünge değişimlerine ilişkin cevapları gözlemlenmiştir. Şekil 9'da z-ekseni için doğrusallaştırma noktası etrafında $\pm 2 \mathrm{~mm}$ basamak referans değişimine ilişkin yerdeğiştirme ve akım cevabı gösterilmiştir. Şekil 10 ve Şekil 11'de sırasıyla $\beta$ ve $\alpha$ eksen takımlarına ilişkin $\pm 0.01 \mathrm{rad}$ basamak referans açısal yerdeğiştirme sonuçları sunulmuştur. Sistem 3-serbestlik derecesinde kararlı hale getirilerek \%5'ten daha daha az veya üst aşımsız olarak verilen referansları başarılı bir biçimde takip edebildiği görülmüştür. Manabe kanonik form katsayıları kullanımı üst aşımsız bir cevabı öngörmektedir. Fakat özellikle Şekil 9 ve Şekil 10'daki cevaplarda makul seviyede \%5'ten daha küçük miktarlarda üst aşımla karşılaşılmıştır. Bunun temel nedeninin modellenmeyen dinamiklerin ve parametre belirsizliklerinin olduğu sonucuna varılmıştır. İlgili $\gamma 1$ katsayısının 2,5 'in birazcık üzerinde $(\sim 2,65)$ alınmasıyla üst aşım problemi kolay bir şekilde çözülebileceği öngörülmektedir. İkinci bölümde ise 
denetleyici performanslarının dış bozucu giriş karşısındaki performansı gözlemlenmiştir. Doğrusallaştırma noktası etrafinda kararlı kontrolü sağlana sisteme $2,7 \mathrm{~kg}$ 'lık bir yük, ağırlık merkezinden daha uzak bir noktaya $t=2,9 \mathrm{~s}$ zamanı civarında uygulanmış ve $t=7,7 \mathrm{~s}$ civarında uzaklaştırılmıştır. Bu duruma ilişkin yerdeğiştirme ve akım cevapları Şekil 11 - 13'de verilmiştir. Dengesiz yüklemeye karş1lık gelen bu durumda kararlılık korunmuş, yükleme ve yük uzaklaştırma anlarında yerdeğiştirmelerde sapmalar görülmüş fakat kalıcı rejime geçildikten sonra yerdeğiştirmelerin doğrusallaştırılan değere yakınsadığı görülmüştür. Önerilen taşıtın yastıklama kontrolü deneysel çalışmalarla başarılı bir biçimde gösterilmiş, denetleyici tasarımında öngörülen performans kriterlerine hem referans takibinde hem de bozucu giriş uygulanması durumunda ulaşılmıştır. Özgün taşıt konfigürasyonu literatüre tanıştırılmıştır. Kanonik polinom yaklaşımı ile denetleyici tasarımı sadece manyetik yastıklama için değil pek çok hareket kontrol tasarımı içinde kolay bir biçimde katsayı diyagramı metoduyla kullanılabilir. Gelecekte sistemin düzlemde doğrusal motorlarla sürülme çalışmaları yapılacak ve literatüre sunulacaktır.

\section{TEŞEKKÜR (ACKNOWLEDGMENTS)}

TÜBITTAK ARDEB Başkanlığı'na 112M210 nolu proje kapsamında, YTÜ BAP Koordinatörlüğü'ne 2013-06-04-KAP01 nolu proje kapsamında vermiş oldukları destekten dolayı teşekkür ederim.

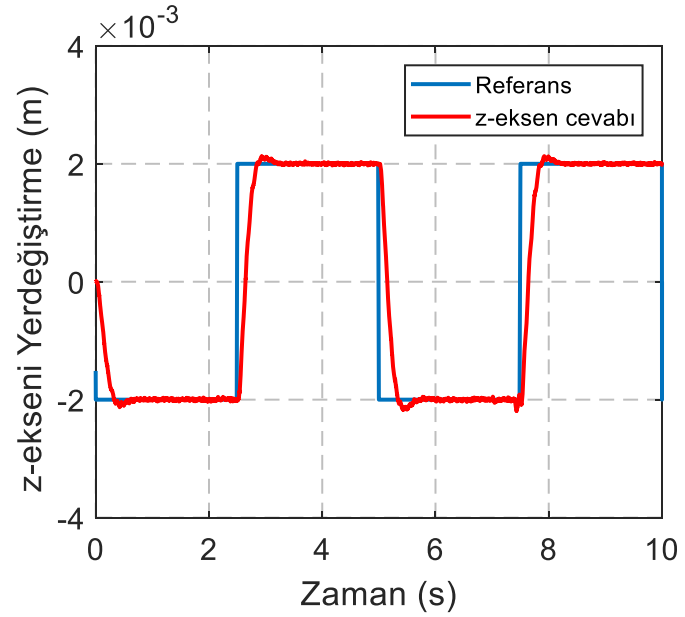

(a)

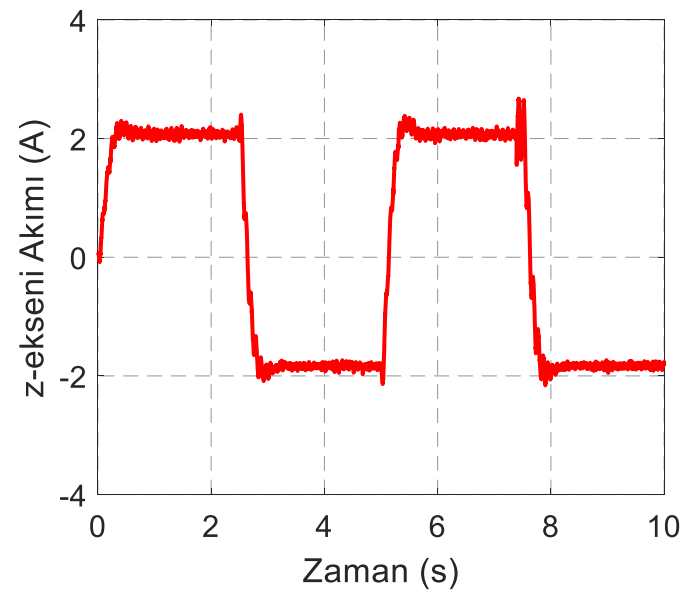

(b)

Şekil 9. z-ekseni basamak giriş cevabı; (a) yerdeğiştirme, (b) akım

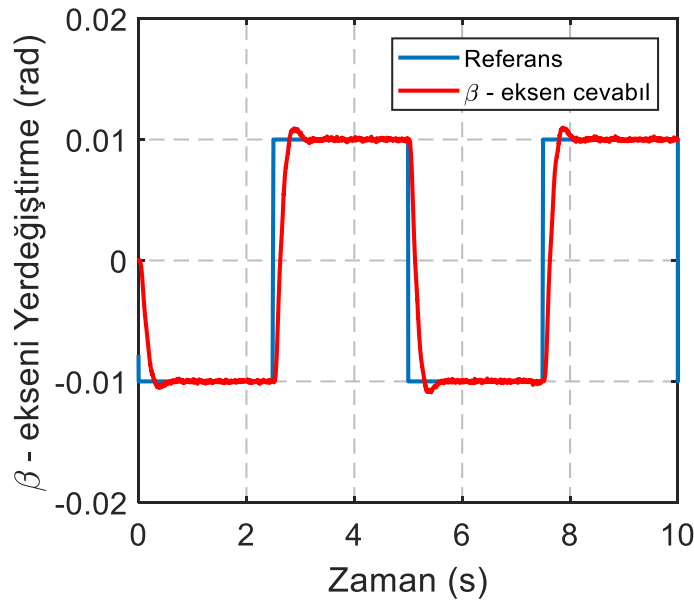

(a)

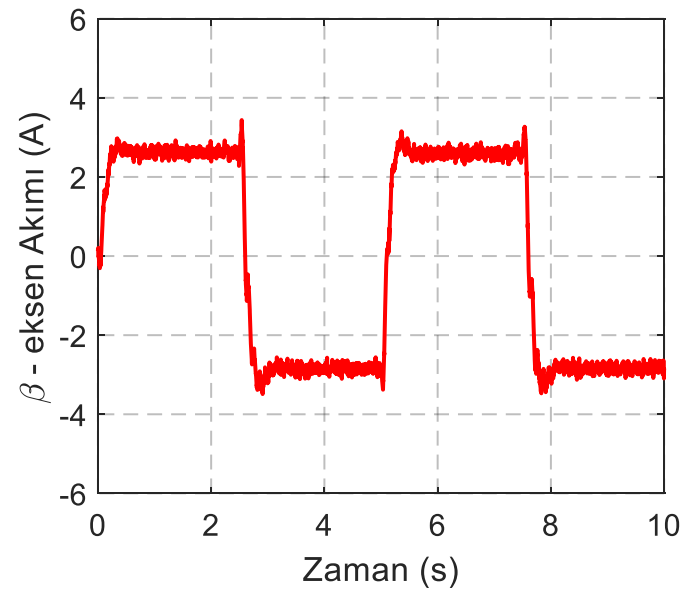

(b)

Şekil 10. $\beta$-ekseni basamak giriş cevabi; (a) yerdeğiştirme, (b) akım 


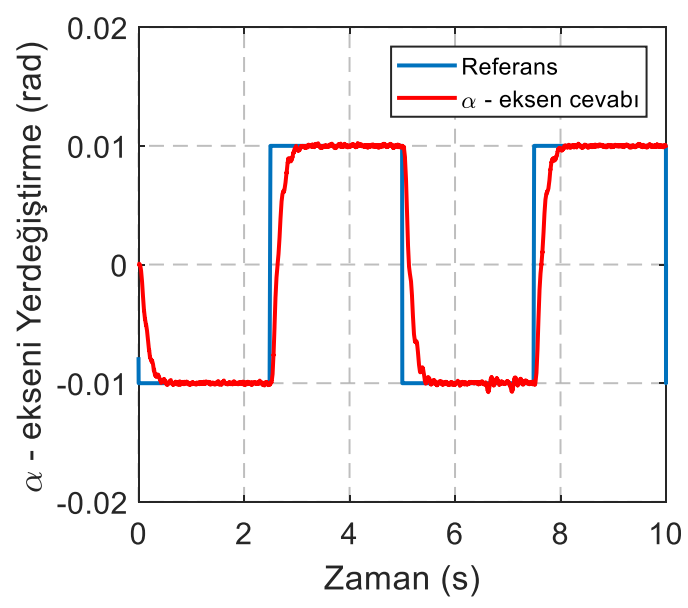

(a)

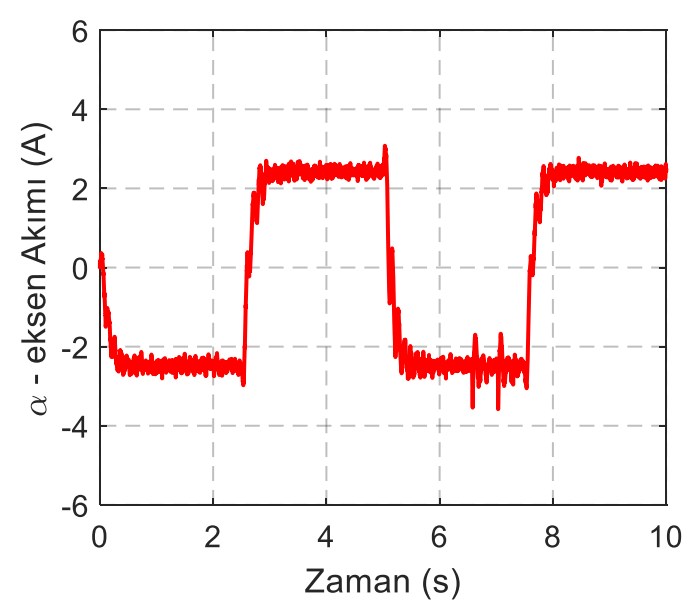

(b)

Şekil 11. $\alpha$-ekseni basamak giriş cevabı; (a) yerdeğiştirme, (b) akım

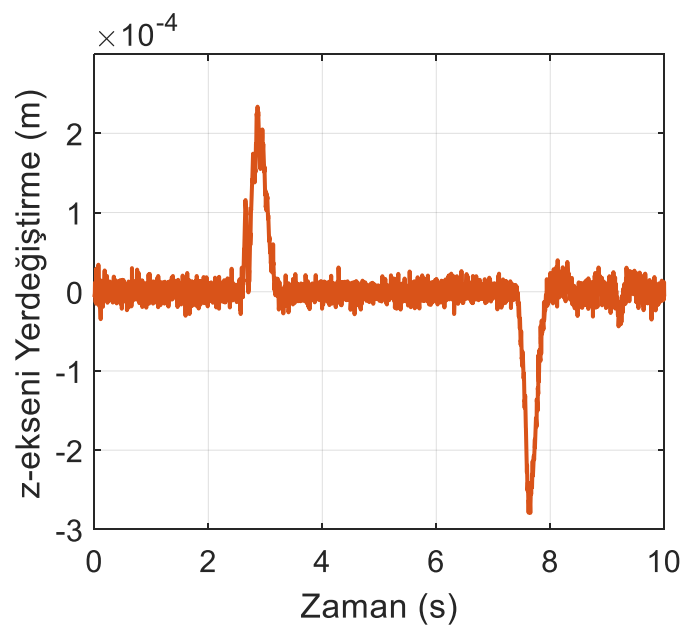

(a)

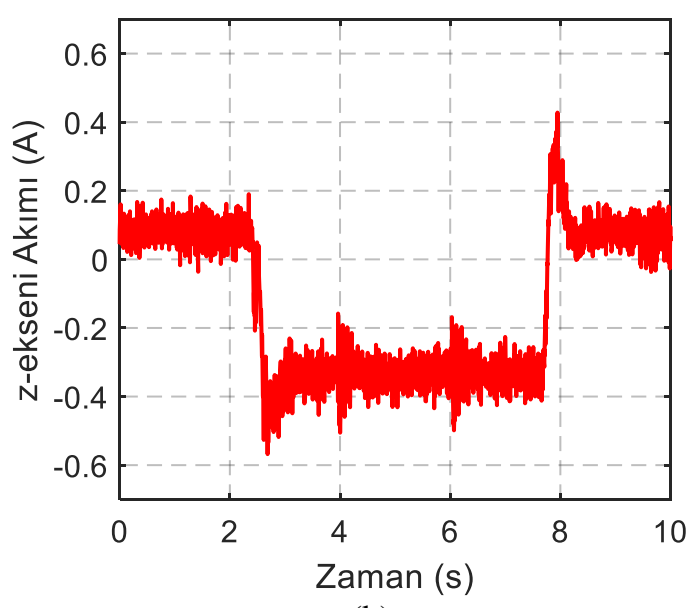

(b)

Şekil 12. z-ekseni bozucu giriş cevabı; (a) yerdeğiştirme, (b) akım

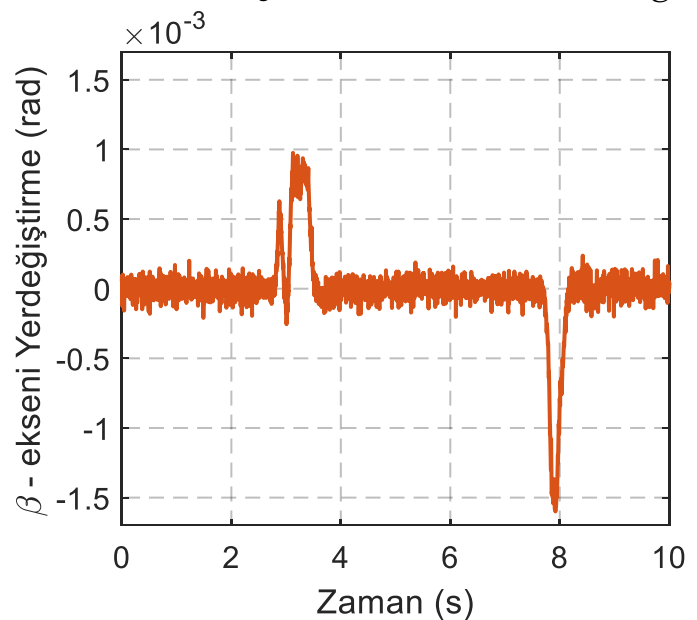

(a)

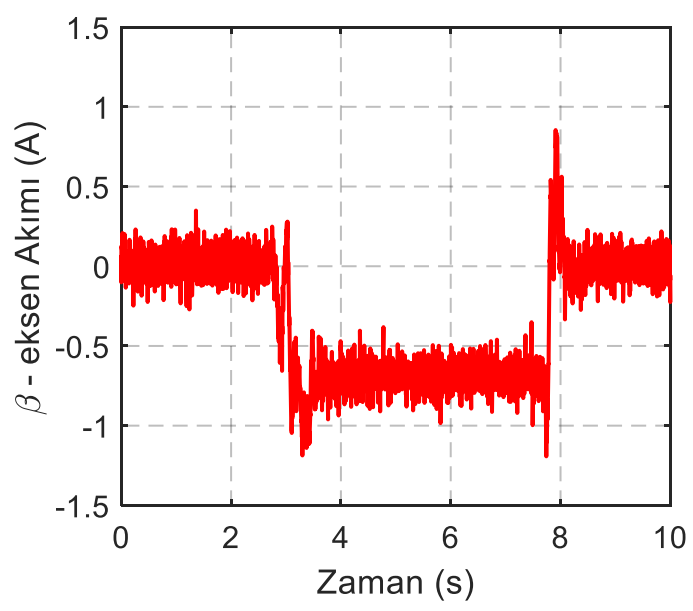

(b)

Şekil 13. $\beta$-ekseni bozucu giriş cevabı; (a) yerdeğiştirme, (b) akım 


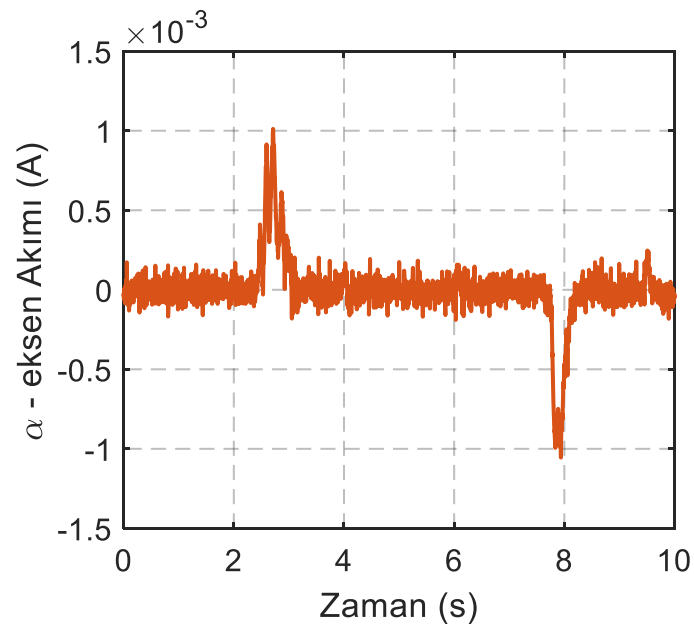

(a)

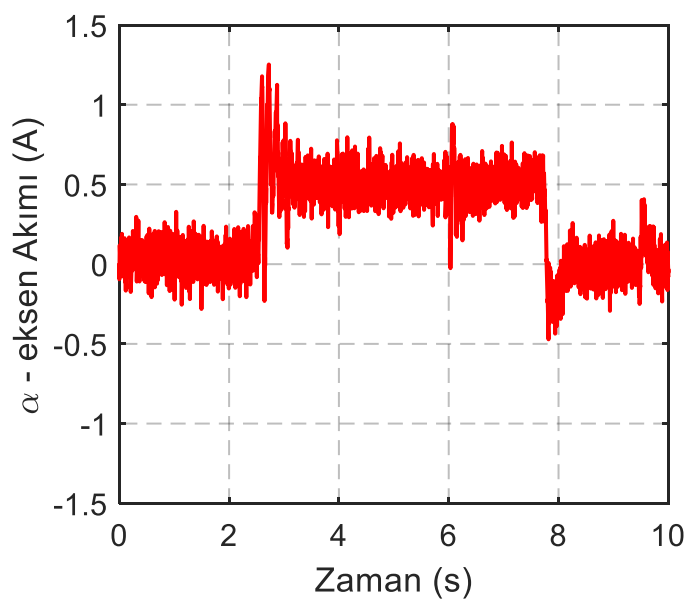

(b)

Şekil 14. $\alpha$-ekseni bozucu giriş cevabl; (a) yerdeğiştirme, (b) akım

\section{KAYNAKLAR (REFERENCES)}

[1]SINHA, P. K., Electromagnetic Suspension, Dynamics and Control, Peter Peregrinus Ltd., London, U. K., 1987

[2]HAN, H. S., KIM D. S., Magnetic Levitation: Maglev Technology and Applications, Springer, 2016

[3]MAKINO, Y., ERKAN, K., KOSEKI, T.,"Six Degrees of Freedom Control through Three Hybrid Electromagnets and Three Linear Motors for Two Dimensional Conveyance System", SEAD 2004, The 16th Symposium on Electromagnetic and Dynamics (SEAD), 87-90 Kita Kyushu, Japan, June 2004

[4]ERKAN, K., KOSEKI, T., "Fuzzy model based nonlinear control of an active oscillation suppression system comprised of mechanically flexible elements and triple configuration of u-shaped electromagnets", 9th IEEE International Workshop on Advanced Motion Control, 698-703, Istanbul, Turkey, 2006

[5]ERKAN, K., YALÇIN, B. C., GARIP, M., "Three-axis gap clearance I-PD controller design based on coefficient diagram method for 4-pole hybrid electromagnet", Automatika: Journal for Control, Measurement, Electronics, Computing and Communications, 58:2, 147-167, 2016

[6]BOJAN-DRAGOS, C. A., PREITL, S., PRECUP, R.-E., et al. "State feedback and proportionalintegral-derivative control of a magnetic levitation system", IEEE 14th International Symposium on Intelligent Systems and Informatics (SISY), 111-116, 2016

[7]ZHANG, J., TAO, T., MEI, X., JIANG, G., ZHANG, D., "Non-linear robust control of a voltagecontrolled magnetic levitation system with a feedback linearization approach," Journal of Systems and Control Engineering, Proceedings of the Institution of Mechanical Engineers, Part I, 225, 85-98, 2011.

[8]SUNG-KYUNG, H., LANGARI, R., "Robust fuzzy control of a magnetic bearing system subject to harmonic disturbances", IEEE Trans Contr Syst Technol., 8-2, 366-371, 2000.

[9]SU K. H., LI, C. Y., "Supervisory fuzzy model control for magnetic levitation system", IEEE 13th International Conference on Networking, Sensing, and Control (ICNSC), Mexico City, Mexico, 2016

[10]CHO, D., KATO, Y., SPILMAN, D., "Sliding mode and classical controllers in magnetic levitation systems”, IEEE Control Syst., ;13-1, 42-48, 1993. 
[11]CHUNFANG, L., ZHANG J., "Design of second-order sliding mode controller for electromagnetic levitation grip used in CNC", 24th Chinese Control and Decision Conference (CCDC), 3282-3285, Taiyuan, China, 2012

[12]CHIANG, H. K., TSENG, W-T., FANG C-C., et al."'Integral backstepping sliding mode control of a magnetic ball suspension system", IEEE 10th International Conference on Power Electronics and Drive Systems (PEDS), 44-49, Kitakyushu, Japan, 2013

[13]PHUAH, J., LU, J., YASSER, M., YAHAGI, T., "Neuro-sliding mode control for magnetic levitation systems," IEEE International Symposium on Circuits and Systems, 5, 5130-5133, 2005.

[14]WANG, B., LIU, G.-P., REES, D., "Networked predictive control of magnetic levitation system," IEEE International Conference on Systems, Man and Cybernetics, 4100-4105, 2009

[15]ASTRÖM, K.J., HAGGLUND, T., PID Controllers: Theory, Design and Tuning. 2nd Edition. Research Triangle Park, NC: Instrument Sociaty of America, 1995

[16]VERMA, S. K., YADAV, S., NAGAR, S. K., "Optimal fractional order PID controller for magnetic levitation system", 39th National Systems Conference (NSC), Noida, India, 2015

[17]SINGH B., KUMAR, V., "A real time application of model reference adaptive PID controller for magnetic levitation system", IEEE Power, Communication and Information Technology Conference (PCITC), Bhubaneswar, India, 2015

[18]MANABE, S., "Coefficient Diagram Method", 14th IFAC Symp. on Automatic Control in Aerospace, Seoul, 211-222, 1998

[19]HAMAMCI, S. E., “A robust polynomial-based control for stable processes with time delay", Electrical Engineering, 87, 163-172, 2005 